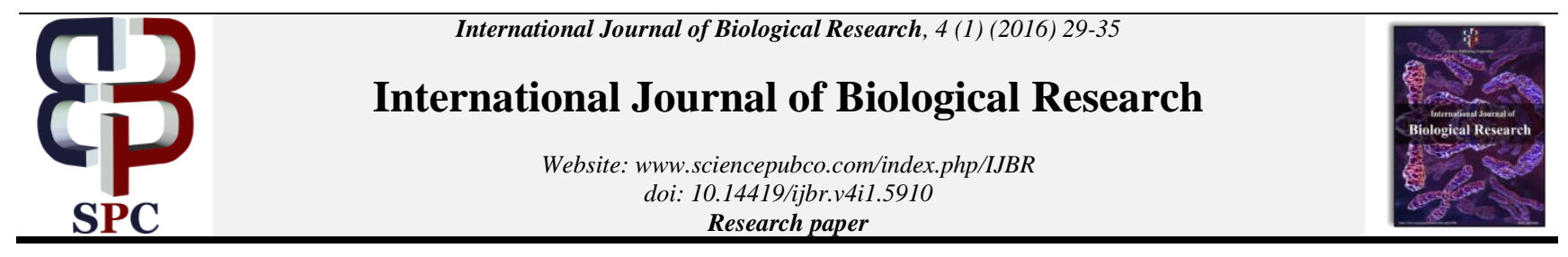

\title{
Effect of mercury (HG) on some biological parameters of channa punctatus
}

\author{
Yogesh Kumar Gupta ${ }^{1}$, Pravesh Kumar ${ }^{2}$ \\ ${ }^{1}$ Yug Chetna Mahavidyalaya Sumerpur, Hamirpur (U. P.), (Affiliated by Bundelkhand University, Jhansi) India \\ ${ }^{2}$ Bundelkhand University, Jhansi (U. P.), India \\ *Corresponding author E-mail: yogeshgupta.880@ rediffmail
}

\begin{abstract}
Freshwater fish, channa punctatus caught from Yamuna river studied for toxicity and biological parameters. In the present study shortterm $(96 \mathrm{hr})$ toxicity of mercury in relation to estimation of hematological test for channa punctatus. The control fishes showed mean value of $75.00 \mathrm{~g} / \mathrm{dL}$ for hemoglobin. The fishes were exposed to sub- lethal concentration of mercuric chloride showed the hemoglobin mean values of $67.2,50.8,42.6$ and $29.2 \mathrm{~g} / \mathrm{dL}$ hemoglobin at $0.02,0.04,0.06,0.08$, and $0.10 \mathrm{ppm}$ treatment respectively. The values for treatments showed a significant decrease when compared to the control (P-0.05). The heavy metals has a direct effect on the 96-hr LC50 values of the respective heavy metals and the susceptibility of fish.
\end{abstract}

Keywords: Heavy Metal; Mercuric Chloride; 96-Hrlc50 Value; Channa Punctatu.

\section{Introduction}

Presently population of India is increasing very rapidly. In this situation of food is a common problem. A large part of population uses fish as alternative food because it is cheap \& easily available source of food.

Carps and catfishes from a major part of the edible variety among the fresh water fish. While growing in the polluted water, these fishes are affected by the toxic heavy metals are consumed by the human being as food. In this ways these heavy metals may pass into the human systems causing undesirable effects on the health of its consumers.

Pollution of water ultimately affects human health. Water is as indispensable natural resource on this earth on which all life depends. The earth's surface is covered by water and most of the animals and plant have $60-65 \%$ water in their body. With increasing human population and rapid development like urbanization and industrialization water pollution is also increasing.

Environmental pollution can, therefore by defined as an undesirable change in the physical, chemical or biological, characteristic of any component of the environment (air, water, soil) which can cause harmful effects on various from of like or property. 'In addition of any substance to water or change in water's physical \& chemical is called as water pollution."

The chief sources of water pollution are sewage and other waste, like industrial effluents, fossils fuels and Nuclear power plants. A wide variety of both inorganic and organic pollutants is present in effluents from tanneries textiles, paper and pulp mills. The pollutants include plastics, metallic waste, toxins, acids, salts, DDT etc., $\mathrm{Na}, \mathrm{Cu}, \mathrm{Cr}, \mathrm{Cd}, \mathrm{Hg}, \mathrm{Pb}$ etc. are the heavy metals effluents discharged from industries. Some heavy metals like Mercury, Mercury and Cadmium cause various types of disease. Mercury dumped into water soluble Methyl Mercury accumulators in fishes. Mercury is considered a devastating environmental pollutant, mainly after the environmental disaster at Minamata and several other poisoning accidents due to the use of Mercury pesticides in agriculture.

Pollution by heavy metal Mercury had caused the disease called Minamata. The disease was caused by mercury contaminated rice. In this disease bones, liver, pancreases, kidney, lungs are affected. The effect of metals on water bodies and waste water range from beneficial through troublesome to dangerously harmful or toxic Biological assimilation to heavy metals depends on their forms found in water. It has been determined that physical \& chemical form of heavy metal effects toxicity. It is known that ionic form of heavy metals is most toxic.

The heavy metal pollution of aquatic ecosystems is often most obvious in sediments, macrophysics and aquatic animals, than in elevated concentration in water. Therefore aquatic ecosystem is typically monitored for pollution of heavy metals, using biological assays. Many aquatic insects, fish protozoa, plants and crustaceans. Fish species are often the top consumers in aquatic ecosystems and thus metal concentration in fish can act as an environmental indicator of the state of the environment.

Presences of some heavy metals in the biological system are very useful to us. Such as Iron in blood and Magnesium in chlorophyll. Deteriorating effects of metals or metal ions are effectively exhibited by the transfer of Methyl mercury from insecticides and pesticides, through animals, plant and water to human systems. Similarly chromium of industrials waste effects the life and growth of fishes. Industrial discharge of heavy metals as their wastes cause land and water pollution. Consequently terrestrial and aquatic fauna and flora are affected in various beneficial ways.

The heavy metals that are harming the aquatic life are lead, Mercury, Chromium, Cadmium, Silver and Iron. Methyl has been found as a byproduct in the insecticide, paints and pharmaceutical industries. The use of mercury, arsenate, phenyl, lead acetate, zinc cyanide, arsenic chloride and methyl mercury as insecticide, fungicide, herbicide and disinfectants is agriculture. Mercury has been detected in the effluent waste of industries. Nickel finds extensive use in edible oil industries, in hydrogenation of fats and 
oils. In this manner the heavy metals discharged from various industries, are getting their way to water bodies along with the effluent water. Fish are acknowledged to be the single largest source of lead for man. In some instance, fish catching was banned for human consumption because their total mercury content exceeds the maximum limit recommended by the FAO \& WHO.

Heavy metal mercury the black listed element by environmentalists is released into the environment by several sources. Alkali and metal processing, incineration of coal, medical waste, mining of gold contribute greatly to mercury concentration in some areas, but atmospheric deposition is the dominant source of mercury over most the large scope. Once in the atmosphere, mercury is widely disseminated and can circulate for years, accounting for its wide-spread distribution. Natural sources of atmospheric mercuric chloride include volcanoes, geological deposits of mercuric chloride and volatilization from the ocean. Although all rocks and, sediments, water, and soils naturally contain small but varying amount of mercury. Scientists have found some local mineral occurrences and thermal springs that are naturally high in mercury. The discharge of effluents containing mercury into the environment has caused grave contamination problems in communities in human population. Cases such as minamata and Nighata in Japan, during the 1956s and 1960s, and in Iraq in the 1970s reflect high risk from this type of pollution. This stirred the attention of health authorities in relation to the contamination of rivets by industrial waste containing mercury, because besides being the most toxic among heavy metals, it is also accumulated in animals for long period of time.

It cannot be broken down in the environment, only it's from can change. All forms of mercury are extremely toxic.

Aquatic organisms produced in breeding systems are constantly exposed to pollutants, since the water utilized in the production processes originates from rivers, lakes or sources that could be contaminated with $\mathrm{Hg}$. Tavares (1995) showed that for aquatic organism to develop and survive well, the condition of the environment in which they live is of fundamental importance. The introduction of any substance in the water produce changes in its quality which is not always favorable to the development and survival of aquatic organism. Aqua cultural organisms may bioaccumulation trace metals in their tissues and consequently threaten themselves directly toxicity tests laboratory performed are used extensively to predict the effect of chemicals in aquatic ecosystems (Tsai et al., 1995).

Mercury as an industrial pollutant and immune toxicant has the potential to adversely affect human and animal health. It induces a broad range of physiological, biochemical and neurological dysfunctions in human (Nordberg et al., 2007). The use of haematological variables, such as ion and glucose concentrations, hemoglobin and haematocrit indicate a physiological response to a contaminated environment (Dethloff et al., 2001). The count of red blood cells is quite a stable index and the animal body tries to maintain this count within the limits of certain physiological standards using various physiological mechanisms of compensation (Al-Akel et al., 2010). Studies have shown that water quality is affected by toxicants; any physiological changes will be reflected in the values of one or more of the haematological parameters (Van Vuren, 1986). Blood cell responses are important indicators of $n$ the internal and/or external environment of animals. However, in the fish these parameters are more related to the response of the whole organism, that is, to the effect o fish survival, reproduction and growth. Fish live in very intimate contact with their environment, and are therefore very susceptible to physical and chemical changes which may be reflected in their blood components (Wilson and Taylor, 1993). Blood tissue truly reflects physical and chemical changes occurring in organism and an early diagnosis is also possible when evaluating haematological data, particularly blood parameters (Luskova, 1997).However, it should be noted that hematological indices are of different sensitivity to various environmental factors and chemicals (Vosyline, 1999). Previous hematological study of nutritional effects, infectious diseases and pollutants brought the knowledge that erythrocytes are the major and reliable indicators of various sources (O'neal and Weirich, 2001; Ehulka, 2002). This study, therefore, assessed the hematological profile of clarias gariepinus exposed mercuric chloride. Moreover, change in plasma glutamicoxloacetic transaminase (PGOT) and plasma glutamic-pyruvic transaminase (PGPT) activities also indicate the influence of water pollution on fish (Bucher and Hofer, 1990).

Fish species constitute a significant component of the food chain between the aquatic Environment and man. Consequently, heavy metal studies are carried out on fish samples for aquatic Environment pollution monitoring (Fonkou et al., 2002; Zehra et al., 2003; Ashraf; 2006; Dimari et al., 2008 because they bio-accumulate these metals significantly in their tissue. A number of factors such as concentrations; the chemicals form of the metals in aquatic Environment portal of the access and physiology of organ where accumulation take place have been attributed to the bioaccumulation. Processes of these metals in fishes (Protasowicki and morsy ), 1993; USEPA, 2000; Staniskie nel et al., 2006 Vinodni and Narayanah, 2008

Some evidence supports a progressive increase in concentration from one tropic level to the next higher level of mercury in aquatic food chains. In comparison to benthic feeding fish, the fish that feed on plankton, invertebrates and vertebrates, the greatest Mercury concentration were found in piscivorous fishes. The effects of exposure to Mercury have been studies extensively in fish. The uptake of Mercuric chloride is proportional to the concentration of Mercury in water. However, the uptake of methyl mercury chloride if fish increases with increased water temperature, exposure concentration, size and age to the fish, breeding status and food ingestion rate.

According to Oliveira- Riberio et.al, (1996) and Machado and fanta (2003), through studies utilizing fish under controlled condition provide, through the evolution of motality, behavioral, reproductive success hematological changes and damage to tissues, important information corresponding to the effect of pollutants on the biota of natural aquatic ecosystem.

The study of different biochemical and cellular constituents in blood is one of fundamental important in the physiological and psychopathological evolution of animals, because morphological and quantitative variations in blood parameters can be induced by pollutants and other environment factors- (Juneja and Mahagang 1983; Ranazani - Paira et. al, (1995), the study of the hematological change in different stress condition such as exposure to heavy metals.

Change in the hematological profile of the fish exposed to mercuric chloride has been observe in Haplias Malabaricus (Oliveria Riberio et. al, 2006), Tilapia mossambica (Menezes and Quasim, 1984), Onechromis aureus (Allen, 1994) Acipensen baerie (Milkyaakov and Lapirova, 1996), Ctenopharyngodon idella (Shakoori et. al, 1994) Pleuronectes Platessa (Fletcher \& White, 1986), Aphanius dispar (Himly et al., 1980).

Channa punctatus is one of the most important fresh water fin fish in aquaculture wand among the numerous regions now inhabited by Channa punctatus many are under threat from metal pollutants including mercury. There are many works using this species in bioassay tests in order to learn the effects of chemicals in aquatic ecosystems.

A number of hematological indices such as hematocrit (Hct.) Hemoglobin ( $\mathrm{Hb}$ ) red blood cells (RBCs) and so on are used to assess the functional status of the oxygen carrying capacity of the oxygen blood stream and have been used as indicator of metal pollution in the aquatic environment (Shah and Alitindag, 2004a). The survey of the health of workers involved in mining and processing sectors has revealed that heavy metal mercury have a number of ill - effects on their health.

In the present work tempts attempts have been made to study the effect of heavy metal mercury on fresh water fishes Channa punctatus. Channa punctatus was utilized as the modal organism in this study, because it has well-documented general biology, short development time easy culturing and year round reproduction. Be- 
cause the characteristic of channa punctatus was considered suitable for toxicity test.

Mostly hematologies of fishes are studied for seeing the effect of mercuric chloride. Mercuric chloride affects edible fresh water fishes which is hazardous for human begins. That is why this present work is also based on study of biological parameters.

The studies have been made largely with reference to the growth and physiology of the snake head fish species Channa puntatus. The extent of the toxicity of metal in fishes has been studies at varying concentration of metals mercuric chloride. The purposes of this study are to evaluate toxic effect of mercuric chloride on snake head fish determining some biological parameters changes in behaviors and mortality of Channa punctatus

\section{Objectivs}

The main objective of our study is analyzing the impact of sub lethal concentration of mercuric chloride on biological parameters of snake head fish channa punctatus.

1) To determination of $\mathrm{LC}_{50}$.

2) Estimation of Haematological.

3) To study the biological parameters change by mercuric chloride treated experimental animals.

\section{Review of literature}

The need of the industrial development has grown many folds in the present day's civilized society. Heavy metals are being passed on in to aqueous environments through industrial, sewage disposal, soil leaching and rainfall. The concentrations of these heavy metals are sub interval to aquatic organism, when the duration of exposure to these metals are prolonged. Heavy metals form several industrial mining and other sources enormously contribute to the pollution problem in rivers and stream resulting in adverse impacts on biota including fishes. There is growing scientific consensus that numerous industrial and agricultural chemicals have the ability to interfere with various activities of all animals including fishes.

The bioassay techniques for marine and fresh water fishes and method of data interpretation have been well documented by Duodoroff (1957), Sprague (1969, 1970, 1971), Stephan \& mount and Stephan $(1973,1982)$. Sprague presented an excellent review on apply bioassay resulting from measurement of pollutant toxicity in fishes. R.A. fishar designed the statistical method for research workers (1929) standard method for the examination of water and waste has been documented by APHA/AWWA/WEF (1998).

The study on the effect of metals and pollutants (in different species of fishes) has been undertaken by many scientists. The continuous use of pesticides has been increasing their concentration, in the water bodies and unlimitedly affecting the aquatic fauna and flora.

Increases in role of pesticides used in most tropical countries have reported severe toxicities, bioaccumulation and reduction of fish production in rice-fish culture (I. Palmer, 1972; Parish. P.R., 1985 A.G. Cagauan \& A.R. Arce, 1992). Comparative toxicology of insecticides for vertebrate wild life and fish is studied by Tucker and Leitzke (1984) which have the factor to produce change in toxic value of various test system. The factors causing difference between species are observed. Finally the factors wear related to the differences in effects, between chemical environment \& under normal environmental condition in the field.

The toxicity of two organ phosphorus insecticides malathion and phosphomindon in Channa striatus has been studied by Chaudhari et. Al (1984). The toxic effect of malathion and phosphomindon on the fish, channa straitus have been evaluated by the mean of graphical methods and probit analysis. Pesticide toxicity has been studied in a fresh water fish, channa punctatus in the river Kshipra in Ujjain by Sexena and Sehgal (1985). The Carp, Cyprinus carpio exposed to various pollutants such as aldrin, toluene, methanol etc. which has shown the rise in serum glucose and cortisol with the decline in plasma protein and cholerterol contents (Gluth and Hank, 1985). The decreased rate of absorption of two sugars and an amino acid in the faesh water snak head fish channa punctatus have shown the effect of four different concentration of a carbamate pesticide perrormed by Sastry and Siddiqui (1985).

The effect of Toxicity pesticides in fishes has been studies by A.S Murthy (1986).The sub lethal effects of pesticides on non-target aquatic organism may be essential for health and maintenance of the vulnerable highly productive ecosystem are the subjects of intense study by scientists and environmental managers (Mineau, 1991; weaner et. al. 2000; Doran et, al. 2001; Fulton and key, 2011).

Toxic effects of mercury ions for different fish species have also been studied (Gupta and Rajbanshi, 1995; Buhl, 1997; McCary and Heagler, 1997; Sukhovadkaya et al., 2001).

The scope was largely restricted to the evaluation of responses elicited by dosages of chemicals given to fish or wildlife species. The residues produced by the chemical dosage were, important in understanding of the toxicology of insecticides.

The affect of industrial pollutants in climbing perch, Anabas testudineus (Bloch) has been observed by Chatterjee et al.,(1984). Certain stages in life cycles of fresh water fishes are more susceptible to environmental and pollution stresses (Von Westernhagan 1998). The inhibition of head kidney peroxides was usually associated with decrease in iodine peroxides activity and blood thyroxin level. The interrelationship of reduced glutathione (GSH) and Glutathione S-transferees in the liver of a fresh water climbing perch, Anabas testudineus exposed to common industrial pollutant has been studied by Chatterjee et al., (1984). It may be summarized that the majority of xenobiotics of industrial origin are detoxicated by the Glutathione S-transferase pathways enabling the fish to survive exposure to the additive and synergistic toxicity of mixture of poisons.

The studies of the effect of metals in different verities of fish have been undertaken by many scientists. Heavy metals such cadmium, mercury, lead, antimony, nickel, chromium, copper, arsenic etc. are highly detrimental to public health. These metals could be more serious pollutants than the organic pollutants.

The acute toxicity of some heavy metals to Tilapia mossambica has been documented by S.A. Qureshi. et al,(1980). M. K. Alam and U. E. Maughan (1995) have worked on acute toxicity of heavy metals to common carp Cyprinus carpio. Use of dialysis tubing in defining the toxic fractions of heavy metals in naturals waters.

Mercury is one of the most toxic metals and it grouped under European Economic Community's black list pollutants because of its high toxicity, persistence and bioaccumulation in the ecosystem (Moore \& Ramamoorth, 1984). Mercury, a sulfhydryl-reactive heavy metal, exists in very small amounts in the nature. India, a developing country, is at a high risk of environmental pollution, especially the inland water bodies' faces the highest pollution because of uncontrolled industrial effluents, inorganic fertilizers and chemicals used in agriculture (Khaleque \& Elias, 1995; D'monte, 1996). As a potent sulfhydry-reactive compound (Win ski \&Carter, 1985) mercury has been shown to affect Hasan. et al. numerous intracellular singnal transductions pathways causing many alterations in cellular functions (Hossain et al., 2000; Yang \& Frenkel,2002; Hossain et al.,2003; Tabellini et al., 2005).

Mercury occurs naturally in the environment (Church \& Scudlark, 1998) but is primarily introduced into aquatic system through anthropogenic pathways, including effluent containing dyes, fungicides used in agriculture, mining and smelting, chlorine alkali production facilities, industrial waste and emission, and ultimately through atmospheric deposition caused by the combustion of fossil fuels and municipal and medical wastes (Clarkson, 1994; Porcella, 1994).

The work on biological effect of heavy metals and their complexonats with DTPA on fish was done by Kazlauskiene et al., (1999). Waqar Ashraf (2003) have observed levels of selected heavy metals in Tuna fish. Histopathological changes in liver and gill epithelium of Nile tilapia. Oreochromic niloticus exposed to water borne copper had been studied by Fernandes A.F., et al. (2006). 
Once in the acute environment, metallic mercury readily transformed to organic methyl mercury through biological processes that include sulfate reducing bacteria and some fungi (Church \& Scudlark, 1998; Porcella, 1994), greatly increasing its bioavailability to aquatic biota. Fish mainly accumulate mercury through dietry pathways (Jernelov \& Lann, 1971; Phillips \& Buhler, 1978; Rodgers \& Beamish, 1981; Harris \& Snodgrass, 1993; Hall et al., 1997). Piscivorous fish species normally accumulate mercury at faster rates than similarly sized omnivorous, plankrivorous, or benthivorous species (Phillipset et al., 1980; Brouard et al., 1994; Olivero et al., 1998; Neumann \&Ward, Mueller \& Serdar, 2002). In the present study the tissue uptake of $\mathrm{Zn} \mathrm{Cd}$ and $\mathrm{Hg}$ individually by the locally available poor men's fish, Channa punctatus has been examined. Sultana and Rao (1998) studied the bioaccumulation pattern of $\mathrm{Zn}, \mathrm{Hg}, \mathrm{Pb}$ in grey mullet, Mugill cephalus from harbor waters of Visakhapatnam. Kargin (1998) reported that the level of given metal showed significant difference between the tissue of Capocta barroisi. Muscles generally accumulate the lowest level of metals in every seasonal et al. (1998) reported accumulation of copper and lead in the tissue of fresh water fish, Tilapia zilli. Mazan and Fernandez (1999) studied the toxicity and differential of copper in the tropical fresh water fish, Prochilodus scrofa. Karkoc (1999) observed an increase in the uptake of $\mathrm{Cu}$ in the liver, gill and muscle tissues of Tilapia nilotica at low salinities. Abreu (2000) studied accumulation of $\mathrm{Hg}$ in see bass. Karakoc and Dincer (2003) studied the effects of temperature on $\mathrm{Zn}$ accumulation in the different organs of Oreochromis nilotius.

T.R. Booer (1944) saw the behavior of mercuric chloride compound in soil D.J Finney (1971) had evaluated the probit analysis. The work on rapid uptake of mercury ion by goldfish is done by C.E Mckone et al. (1971). N.S Fisher et al., (1972) observed the bioavailability of sediment bound methyl and (1973) recorded the temperature effect on mercuric chloride accumulation toxicity and metabolic rate inorganic mercuric chloride in a marine bivale. J.C. Mecleo et al., in rainbow trout (Salmo gairdneri). The lead acetate removal from waste water with starch xanthate cationic polymer complex had been studied by C.L. Swanson et al., (1973).Mercuric chloride in fish and shell fish a review had documented by A.V.Hlden(1973).

Mercury has wide distribution in the earth's crust and aquatic environmental (Ruvio, 1972 \& Zingde, 1989).With its extensive use in various industries for preparation of medicines, fungicides, insecticides and bactericides its concentration is increasing in the aquatic ecosystem as reported by WHO (1976) and FAO (1986). The prescribed limit for mercuric chloride is $0.5 \mathrm{ppm}$ by WHO as mentioned by Kureishy et al.(1979) and Sanzgiry etal.(1988).

The influences of size, sex and temperature on toxicity of mercury on two species of crayfishes have been observed by M.Hebit et al. (1977). The effect Zinc, Copper and Mercury on channa marulis has been shown by B.S. Khangrot (1981). R.A. Lock et al., (1981) have documented the effect of mercuric chloride on mucous secretion in rainbow trout Salmo gairdneri. Biesinger et al. (1982) Daphnia magna were exposed separately to waterborne concentration of mercuric chloride and methyl mercury. High concentration of total mercuric chloride in tissue were associated with, fewer effects on methyl mercury exposures that the mercuric chloride. The effect of mercuric chloride on the blood and kidney of total fish, Halobatrachus didactylus had shown some hematological and histopathological changes in the fish. The study were undertaken by sarasquete et al., (1982).

Kaviraj (1983) has shown the effect of mercury on the feeding rate of the fish. The breeding was delayed white the production was recorded to be hampered. A trend of reduced mercuric chloride contamination at low selenium concentration $(1 \mathrm{hg} / 1$ of se) with maintenance at control mercury contamination levels at a higher selenium concentration of mercuric chloride has been investigated by Varma and Tonk (1983) have studied the selentite toxicity and mercury selenium interaction in juvenile fish. Acute lethal toxicities of selenium and effect of selenium on mercuric chloride accumulation wear determined in fish water fish species.
Sastry and Rao (1984) have show the effect of mercury (in the form of mercuric chloride) on some biochemical and physiological effects of inorganic mercury and copper in gills of ranbow trout have been observed by P.Y. Dooust et al. (1984). Verma et al. (1985). Verma et al. (1985) observed as interesting phenomenon on the effect of environmental variables such as temperature, dissolved oxygen and $\mathrm{pH}$ on the toxicity of mercury in fish, Notopterus. A clear relationship between the dose toxic chemical and growth rate of the fish, Notopterus. A clear relationship between the dose of toxic chemical and growth rate of the fish rainbow trout has been established by the studies of Crossland (1985). Mercuric chloride poisoning in the fish, Barbus conchonius cause marked haematological anomalises, had been shown by Gill and Pant (1987). The effect of water quality on mercuric chloride concentration of northern, pike (Esox lucius) was studied by N. Ram and Sathyanasean (1986). Studies on the acute toxicity of cooper and mercury alone and in combination with the common guppy peocilia reticulate is done by Khangarot B.S.; et al., (1987).

Observation of various marine and freshwater fish species indicate that tissue concentrations of mercury increase with increasing age (as inferred from length) of the fish. In some species, males have been found to harbor higher mercury levels than females of equal age (World Health Organization, 1989).The intestinal wall in fish is an effective barrier to mercury chloride but are permeable to methyl mercury, which can accumulate preferentially over time in muscle tissue to about $50 \%$ of the total dose (World Health Organization, 1989).

All forms of mercury are extremely toxic. Mercury trace contaminant in the environment, it is especially of great concern because of its toxicity and its special ability to bioaccumulate to levels as high as $100,000 \mathrm{ppm}$ in marine organism (USPHS, 1997), due to is bioavailability.

Cavas (2007) and Boncer et, al. (2004) suggested that aneugenicity and clastogenicity by inorganic mercury.

Ranjan and Benerjee, (1991). Reoainted that due to exposure of mercuric chloride solution, epidermis of fish is damaged and starts screening produce quantity of slime. Mercuric chloride as also been reported to blind with Nucleic acid and in habit protein synthesis (Mehra and Kanwan 1980).

Dhakekar et, al. (1985) reported increase in large lymphocyte, reduction in small lymphocyte and thrombocytes population as also elevation in monocytes neutrophills and eoscinophill cells in Hetropneusts fossils, Channa punctatus and mastacebalus on long term exposure to least effective concentration of mercuric chloride. Channa punctatus is a widely distributed fish which constitutes one of the major fisheries in Asia and Africa some records have hewn that channa fishery contribution about $13 \%$ of over 400 tones of annual fish production from all fisheries sector (Awachine and Ezenwaji, 1989).

Several investigation have been carried out various toxicants with clarias species (Aguigwo, 1998; Maheswaran et al., 2008).

The haematological effects of various heavy metal such as copper, mercury, mercury and cadmium on the haematology of channa species, have been reported with these metals, various physiological and biochemical indices in fish has been investigated and consequently used in various Scientific and ecological studies (KoriSiakpene and Egor, 1999; Rogers et al., 2003; Kori- Siakpene et al., 2006; Maheswaran et al., 2008).

Railo et, al., (1985) reported that the blood parameters of dionostic importance are erythrocyte and leucocytes counts, Hemoglobin, Haematocrit and leucocyte differential counts would readily respond to incidental factor such as physical stress and environmental stress due to water contaminants.

The tremendous increase in the use of heavy metals over the past few decades has inevitably resulted in an increased flux of metallic substances in the aquatic environment (Yang and Rose, 2003).

Mercury is a nonessential heavy metal; however, it is considered as one of the most toxic water contaminated and could cause toxicity at each level in organisms, from A large part of these elements in the form of the heavy metal ions are toxic or carcinogen- 
ic in nature and pose a threat to human health and the environment (Damien et al., 2004; Farombi et al., 2007).

\section{Material and method}

In the present investigation toxicity of heavy metal mercuric chloride of fresh water fish Channa punctatus has been studied. The effect of mercury in the form of mercuric chloride, on Channa punctatus were determined by APHA (1985) and EIFAC (1983).

\subsection{Material}

\subsubsection{Chemicals}

The chemical used for the treatment given to the fish is mercuric chloride. The chemicals were of analytical grade purity as packed by E. Merck. These chemicals are-

1) Mercuric chloride $\left(\mathrm{HgCl}_{2}\right)$.

2) Formalin solution for preservation of organs.

3) Chloroform

4) Potassium permanganate $\left(\mathrm{KMno}_{4}\right)$.

\subsubsection{Mercuric chloride}

Chemical Name: Mercuric chloride Synonym: Chalomal, Carosive sablimate Appearance: White crystal or powder Odour: Odourless

Solubility: $7.4 \mathrm{~g}$. In $100 \mathrm{~g}$ of powder PH: 3.2 (0.2 M Solution) Boiling point: $302^{\circ} \mathrm{C}(576 \mathrm{~F})$ sublimes Melting point: $277^{0} \mathrm{C}(529 \mathrm{~F})$ sublimes Vapour pressure $(\mathrm{mm} \mathrm{Hg}): 136.2^{0} \mathrm{C}$ Chemical formula: $\mathrm{Cl}-\mathrm{Hg}-\mathrm{Cl}$

Molecular formula: $\mathrm{HgCl}_{2}$ Commercial formation of mercuric chloride (Central drug house Pvt. Ltd., Pune) was used in the study.

\subsubsection{Mercuric chloride}

Chemical Name: Mercuric chloride Synonym: Chalomal, Carosive sablimate Appearance: White crystal or powder Odour: Odourless

Solubility: $7.4 \mathrm{~g}$. In $100 \mathrm{~g}$ of powder

PH: 3.2 (0.2 M Solution)

Boiling point: $302^{0} \mathrm{C}(576 \mathrm{~F})$ sublimes

Melting point: $277^{0} \mathrm{C}(529 \mathrm{~F})$ sublimes

Vapour pressure (mm $\mathrm{Hg}): 136.2^{0} \mathrm{C}$

Chemical formula: $\mathrm{Cl}-\mathrm{Hg}-\mathrm{Cl}$

Molecular formula: $\mathrm{HgCl}_{2}$ Commercial formation of mercuric chloride (Central drug house Pvt. Ltd., Pune) was used in the study.

\subsection{Method}

\subsubsection{Experimental animal}

The Channa punctatus has been selected for the present investigation. Healthy specimen of Channa punctatus were obtaining from Betwa River for the help of fisher man and transported in container to the laboratory. This source was selected from the supply of fish since there is no agriculture land or industries nearby Channa punctatus measuring $15-18 \mathrm{~cm}$. in length and weighting about $12 \mathrm{gm}$ were used in the experiment.

\subsubsection{Collection and maintenance of fish}

The fish on which the effect of metallic pollutant is being studied are Channa punctatus. These fished collected from Betwa River in Jhansi and were kept in the laboratory of department of zoology in
Bundelkhand University, Jhansi. The fish were handled very softly to avoid any injury to them.

The collected fished were treated with $0.1 \% \mathrm{KMnO}_{4}$ solution for removal of any fungal infection. The fishes were acclimatized in the ordinary tap water in the plastic pool for 25 days and laboratory condition. The fish were maintained on a photoperiod with $12 \mathrm{~h}$ light/ $12 \mathrm{~h}$ dark during acclimatization.

And the experimental fish were fed only with pieces of chicken intestine. (Arockiaraj et al., 2004).

Test water qualities were as follows:

- Temp : $27.5^{0} \mathrm{C} \pm 1.5^{0} \mathrm{C}$

- $\mathrm{PH}: 7.5 \pm 0.03$

- Dissolved oxygen : $6.4 \pm 0.2 \mathrm{mg} / 1$

- Alkalinity : $2.5 \pm 2.8 \mathrm{mg} / 1$

Determination of $\mathrm{Lc}_{50}$

The $24 \mathrm{hr}$., $48 \mathrm{hr}$., $72 \mathrm{hr}$., $96 \mathrm{hr}$. LC50 value of mercuric chloride was found to be $0.106 \mathrm{ppm}$ in Channa punctatus using the Probit analysis method described by Finney (1971).

Preparation of Stock Solution

Stock solution of mercuric chloride was prepared by dissolving analytical grade mercuric chloride in double distilled water. Acute toxicity of mercuric chloride to Channa punctatus was determined using a standard static renal technique (APHA, 1989) desired concentration of mercuric chloride stock solution in double distilled water. The toxicant in the test chambers was renewed completely with fresh solution of the same concentration every $24 \mathrm{hr}$.

Treatment schedule

After determining LC50 24 hr., 48 hr., 72 hr., 96hr. value 5 sub lethal concentration of mercuric chloride were taken and 5 fishes were introduce in each concentration. For each sub- lethal exposure 5 replicates were maintained. Even through the water was changed every day in the control and the treatment group. The concentration of mercuric chloride remained the same with the experimental period. A facility for oxygenation of the test solution was provided.

Table 1: The Experimental Animals were Divided In Six Groups.

\begin{tabular}{|c|c|}
\hline Group-I(Control) & Normal \\
\hline Group-II(Exposure) & $\begin{array}{l}\text { Mercuric Chloride } 0.02 \mathrm{ppm} \text { once daily for } 35 \\
\text { days }\end{array}$ \\
\hline Group-III(Exposure) & $\begin{array}{l}\text { Mercuric Chloride } 0.04 \mathrm{ppm} \text { once daily for } 35 \\
\text { days }\end{array}$ \\
\hline $\begin{array}{l}\text { Group- } \\
\text { IV(Exposure) }\end{array}$ & $\begin{array}{l}\text { Mercuric Chloride } 0.06 \mathrm{ppm} \text { once daily for } 35 \\
\text { days }\end{array}$ \\
\hline Group-V(Exposure) & $\begin{array}{l}\text { Mercuric Chloride } 0.08 \text { ppm once daily for } 35 \\
\text { days }\end{array}$ \\
\hline Group-VI(Exposure) & $\begin{array}{l}\text { Mercuric Chloride } 0.10 \mathrm{ppm} \text { once daily for } 35 \\
\text { days }\end{array}$ \\
\hline
\end{tabular}

After 35 days the blood from the control and mercuric chloride treated fishes was obtained and collected in Eppendorf tubes containing EDTA anticoagulants (Mg. Benka et al., 2003). These treated and control blood samples used to estimate the haematological parameters.

Mortility:

The fish which showed not activity and did not respond to mechanical stimuli were counted for morality. Death of 3 fishes occurred during acclimatization period.

The number of dead fish was recorded. Fishes were removed immediately from the test aquarium. No moralities were observed during the experiments.

Behavioral Change:

During the period of experiment we daily observe the behavior of all groups of fishes.

Body Weight:

During the period of experiment we daily observe the body weight of all groups of fishes. At the staining of experiment the average weight of fishes is $12-15 \mathrm{gm}$.

Haematological Study:

Total Count of RBC

Total red blood cells (tRBCs) were counted using an improved Neuban haemocytometer (Shah and Altindag 2004a). Blood was 
diluted 1:200 with Hayens fluid (Mishra et al., 1577). Erythrocytes were counted in the loaded haemocytometer chamber and total numbers were reported as $106 \mathrm{~mm}^{-3}$ (Wintrobe, 1967).

Total Count of WBC

Total white blood cells (tWBCs) were counted using an improved Neuban haemocytometer (Shah and Altindag 2005; Mg. Banka et, al., 2003). Blood was diluted fluid and placed in haematocytometer for large $(15 \mathrm{q} \mathrm{mm})$ corner square of the haematocytometer were counted under the microscope (Olympus) at 640x. The total number of WBC was calculated in mm3x103 (Wintrobe, 1967). Estimation of Hemoglobin:

Hemoglobin $(\mathrm{Hb})$ was determined with a hemoglobin test Kit (DIAGNOVA, Ranbaxy, India) using the Cyanmethmoglobin method. Values of treated groups were compared statistically with control by student t-test. Significant was established at P- 0.05 using the Microsoft excel 2000 programme. Significant of data was further checked with percent change (+ increase and - decrease). In blood parameters of Channa punctatus.

\section{Results}

\subsection{Total RBC count}

The erythrocyte count of healthy controls showed a mean value of $1.77,106 \mathrm{~mm}^{3} \mathrm{He}$ fishes exposed to sub- lethal concentration of mercuric chloride showed mean values of RBCs as 1.66, 1.59, 1.42 and $1.23,106 \mathrm{~mm}^{3}$ for $0.02,0.04,0.06,0.08$, and $0.10 \mathrm{ppm}$ treatment, respectively. The treatment with mercuric chloride was found to inflict a drastic reduction was dosage dependent; as concentration of mercuric chloride increased the RBC levels declines (table). The values mentioned above showed a significant decrease when compared to the control (P-0.05).

\subsection{Total WBC count}

The results of the total count of white blood cells revealed that the blood of the control fish showed a mean value of $6.40, \mathrm{~mm}^{3} \times 103$. The fishes exposed to sub-lethal concentration showed the mean values of WBC as 10.4, 11.9, 12.7, 13.3 and $14.8 \mathrm{~mm}^{3} \mathrm{x} 103$ for $0.02,0.04,0.06,0.08$ and $0.10 \mathrm{ppm}$ of mercuric chloride treatment respectively (table). The value mentioned above showed a significant increase when compared to the control (P-0.05).

\subsection{Estimation of hemoglobin}

The control fishes showed mean value of $75.00 \mathrm{~g} / \mathrm{dL}$ for hemoglobin. The fishes were exposed to sub- lethal concentration of mercuric chloride showed the hemoglobin mean values of $67.2,50.8$, 42.6 and $29.2 \mathrm{~g} / \mathrm{dL}$ hemoglobin at $0.02,0.04,0.06,0.08$, and 0.10 ppm treatment respectively (Table 1). The values for treatments showed a significant decrease when compared to the control (P$0.05)$.

Table 2: Total Count of RBCS, WBCS and Hemoglobin in the Control and Mercuric Chloride Treated Channa Punctatus.

\begin{tabular}{llll}
\hline $\begin{array}{l}\text { Concentration of } \\
\text { Mercuric chloride }\end{array}$ & $\begin{array}{l}\text { No. of RBCs } \\
\left(10^{6} \mathrm{~mm}^{-3}\right)\end{array}$ & $\begin{array}{l}\text { No. of WBCs } \\
\left(\mathrm{mm}^{3} \times 10^{3}\right)\end{array}$ & $\begin{array}{l}\text { Hemoglobin } \\
(\mathrm{g} / \mathrm{dL})\end{array}$ \\
\hline Control & 1.77 & 6.40 & 75.00 \\
$0.02 \mathrm{ppm}$ & 1.66 & 10.40 & 67.20 \\
$0.04 \mathrm{ppm}$ & 1.59 & 11.90 & 50.80 \\
$0.06 \mathrm{ppm}$ & 1.54 & 12.70 & 42.60 \\
$0.08 \mathrm{ppm}$ & 1.42 & 13.30 & 31.60 \\
$0.10 \mathrm{ppm}$ & 1.23 & 14.80 & 29.20 \\
\hline
\end{tabular}

\section{Discussion}

Three major routes of heavy metals intoxication in fish have been suggested by many workers. The first as suggested by Burton et al., (1972) is the coagulation of mucous on gill and damage to the respiratory surface, which results in hypoxia. Seccondly, L.V. Jordanoska et al, (2005) have observed pathological changes in the liver tissue of fish (Barbus meridionalis petenyi Heckel) including parenchyma cell necrosis associated with hemorrhage. The heavy metals affect the organism in such a manner that the entire body of the fish experiences complex biochemical sequences. Through the observation of Srivastave (1982) it is evident that heavy metal in low concentration probably act more through hormone and enzyme disturbance rather than the other suggested routes. While higher concentration may act by producing intense and enzyme disturbance rather than the other suggested routes. While higher concentration may act by producing intense and rapid damage to various systems, resulting in hypoxia, and

In these investigation, mercuric chloride Channa punctatus the form of mercuric chloride which had been subjected to different concentrations of the above mentioned heavy metals. In this chapter an attempt has been made to analyze and correlate the observation.

\subsection{Behavioral change}

In the control condition Group-I fishes showing regular swimming pattern. Later change in swimming pattern was observed. Due to the affect of metal the movement of fishes observed that hypersensitivity \& fast swimming of fish changed into sluggishness after ingestion of metal. This change in behavior of the fish may be due to hormonal imbalance caused by the toxic effect of the metals as suggested by Srivastava (1982). In the present study it was observed that after a brief period of hypersensitivity and fast swimming the fish became sluggish. Howard (1975) and Mc leay (1977) observed the similar phenomenon of impaired swimming stamina in salamon affected by paper mill effluent.

\subsection{Body weight}

During the period of experiment the body weight of all groups of fishes was observed daily. After the fishes were treated with sublethal doses of mercuric chloride a slight decline in their body weight is observed.

Heavy metal contamination may have devastating effects on the ecological balance of the recipient environment and a diversity of aquatic organisms (Farombi, et al., 2007; Vosyliene and Jankaite, 2006; Ashraj; 2005). Fish are widely used to evaluate the health of aquatic ecosystem because pollutants build up in the food chain and are responsible for adverse effects and death in the aquatic systems (Farkas et.al. 2002; Yousuf and El-Shahawi 1999). The decrease in body weight may be due to anaorexia. Similar views has been given by Adams (1977) and Abdel Rehman et al., (1985). In rats after treatment with various oregano phosphorus pesticide.

\subsection{Hematological change}

In recent year hematological variables have been used more to determine the sub-lethal concentration of pollutants (Wedemeyer and Yasutake, 1977). The uses of immune system parameters to asses alterations in fishes experiencing heavy metal exposure and interest in defense mechanism stem from the need to develop healthy management tools to support a rapidly growing aquaculture industry (Jones, 2001).

The results of the present investigation show that mercuric chloride treatment inflicted a drastic reduction in the total count of RBCs. The reduction was dosage dependent.

In the fish Channa punctatus exposed to mercuric chloride hemoglobin percentage decreased significantly. This indicates that mercuric chlorides cause anaemis. This may be due to a decreased rate of production of Red blood cells or an increased loss of these cells Gill and Epple (1993) have attribute anemia to : (I) impaired erythropiesis due to a direct effect of metal on hematopoietic centers (Kidney/Spleen), (ii) accelerated erythroclasia due to altered membrane permeability and/pr increased due to altered membrane permeability and/pr increased mechanical fragility, and (iii) defective Fe metabolism or impaired intestinal uptake of Fe due to mucosal lesions. 
Haematological studies done by Mc Kim et. al. (1976) reported that mercury accumulates in the fish blood. Decline in Hemoglobin and heamatocrit was observed in Channa punctatus exposed to mercury (Sastry and Kamana Sharma. 1980). Thus the accumulated could produce certain haematological and biochemical changes in blood. Haematocrit decreased significantly in the mercury treated fish when compared with the control fish. The distributed hemoglobin synthesis due to an effect of mercury on ALA-D may result in Anemia (Santos and Hall, 1990).

White blood cells play a major role in the defense mechanism of the fish and consist of granules. Monocytes, lymphocyte and thrombocytes. Granulocytes and monocytes function as phagocytes to salvage debris from injured tissue and lymphocytes produce antibodies (Ellis et al., 1978; Wedember and McLeay, 1981). In the present investigation, leucocyte concentration, eosinocyte concentration showed greater and quite different pattern of change with the effect of mercury when compared with the erythrocyte levels of the control group. Blood of all experimental groups contained higher concentration of leucocytes than those of controls. An increase in lymphocyte number may be the compensatory response of lymphoid tissues to the destruction of circulating lymphocytes (Shah \& Altindag, 2005). Allen (1994) observed increased WBC (leucocytes) counts in Oreochromis oureus after mercuric chloride exposure.

The increase in WBC observed in the present study could be attributed to a stimulation of the immune system in response to tissue damage caused by mercuric chloride. Gill and Pant, (1985) have reported that the stimulation of the immune system causes an increase in lymphocyte by an injury or tissue damage. Exposure to mercuric chloride induced variations in differential leucocytes counts and caused lymphocytosis neutrophillia, monocytosis, eosinophilia and thrombocytopenia in Anabas testudineus (kumar et el., 2004). Total WBC count and leucocrit increased in Tinca tinca exposed to lethal and sub-lethal treatments with mercuric chloride (shah and altindag, 2005). Oliveira Ribeiro et al., (2006) observed increase in the leucocytes number in fish hoplias malabaricus exposed to sub chronic and dietary doses of methyl mercury.

\section{Conclusion}

In the present investigation, it has been observed that the metallic pollutant mercuric chloride have affected the fresh water fish Channa punctatus. The concentration of the metallic pollutant affected the fish.The behavior of the fish including swimming movements was also found to be affected by the metallic pollutants. Body weight was observed to be decreased. Hematological parameters changes of fish been studied and found that these hematological parameters are affected by metallic pollutants producing haematological lesions. The present investigation show the mercuric chloride caused immunological deformities in Channa punctatus, which suggest that the metals may weaken the immune system and may result in severe physiological problems, ultimately leading to the death of fish.

\section{Acknowledgement}

We would like to thank the anonymous referee for numerous helpful suggestions

\section{References}

[1] Alam, M.k. and O.E. Maughan (1995): Acute toxicity of heavy metals to common carp (Cyprinus carpio) J.Environ. Sci. Health, Part A: Environ.Sci.Eng. Toxic Hazzard. Subst. control. A 30 (8): 1807-1816. http://dx.doi.org/10.1080/10934529509376303.

[2] Allen, P. (1994). Changes in the hematological profile of the cichlid Oreochromis aureus (Steindancher) during acute inorganic mercuric chloride intoxication. Camp. Biochem physiol C, 108 (1), 117-121.

[3] APHA (1989). Standard method for the examination of water and waste water. APHA, AWWA, WPCF, Washington.
[4] APHA/ AWWA/ WEF (1998). Standard method for the examination of water and waste water, 20th Edn. America Public Health Association, New York, USA, pp. 1976.

[5] Crossland, N.O. (1985). A method to evaluate effects of toxic chemicals on fish growth, CHEMOSPHERE. Vol. 14, No. 11-12, p. 1855-1870. http://dx.doi.org/10.1016/0045-6535(85)90128-6.

[6] Daoust,P .(1981) : Acute pathological effects of mercuric chloride, cadmium and copper in rainbow trout. Ph.D Thesis. University of Saskatchewan, Saskatoon, S.K.

[7] Finney, D.J. (1971). Probit Analysis Cambridge University Press, New York, New Delhi. p.337.

[8] Fisher, R.A. (1929). 'Statistics and Biological Research,' Nature, 24, 266-267. Nordberg, G.F.; Fowler, B.A.; Nordberg, M. and Friberg, L. (2007).Handbook on the Toxicology of Metals. 3rd Edn.Academic press, Amsterdam. ISBN-10:pp. 10-24.

[9] Oliveira-Riberio, C.A.; Neto, F.F.; Mela, M.; Sliva, P.H.; Randi, M.A.F.; Rabitto, I.S.; Alves Costa, J.R.M. and Pelletier, E. (2006), Haematological findings in neotropical fish Hopilas malabaricus exposed to sub-chronic and dietary doses of mercuric chloride, inorganic mercury and tributhltin chloride. Environmental Research, 101, 74-80. http://dx.doi.org/10.1016/i.envres.2005.11.005.

[10] Sastry KV and Sharma K. (1990). Mercury chloride induced hematological and biochemical's anomalies in Ophiocephalus (Channa punctatus). Toxicology Letter. 5: 245-249. http://dx.doi.org/10.1016/0378-4274(80)90067-3.

[11] Srivastava, D.K. (1982). Comparative effects of Copper, cadmium and mercuric chloride on tissue glycogen on the catfish, Heteropneustes fossilis (Bloch).Toxicol. Let. 11:135-135. http://dx.doi.org/10.1016/0378-4274(82)90118-7.

[12] Tavares, L.H.S. (1995), Limnogia Aplicada a Aquiculation. Boletim Tecnico 1. Jabot cabal, SP.Brazil.

[13] Tsai, Ching-lin; Jang, Te-Hsuan and Wang, Li-Hsueh. (1995), Effect of mercury chloride erotonin concentration in the brain of tilapia, Oreochromis mossambicus. Neuroscience Letters, 208-211. http://dx.doi.org/10.1016/0304-3940(94)11208-Z.

[14] Uwah, E.I; Akan, J.C; Moses, E.A; Abah, J; Ogugbuaja, V.O; (2007). Some anion levels in fresh vegetables in Maiduguri Borno State, Nigeria. Agric. J. 2 (3): 392-396.

[15] Veena. K.B.; Radhakrishnan, C.K. et. al. (1997): Heavy metal induced biochemical effects in an estuarine teleost. Indian $\mathrm{J}$. Mar.Sci.26:74-78. 